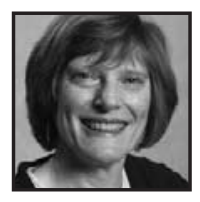

\title{
Crystallization: Teacher Researchers Making Room for Creative Leaps in Data Analysis
}

\author{
Ruth Shagoury, Lewis \& Clark College
}

\begin{abstract}
In this article, the author shares new approaches to data collection and analysis which encourage using "crystallization": an intriguing new method that has emerged in recent years as a kind of three-dimensional data analysis strategy that welcomes the new lens that artistic thinking can bring to conducting and writing research. Examples from teacher-researchers include ways to use storytelling, art, self-reflection, children's books, metaphor, and imagination to expand the field of data collection and analysis.
\end{abstract}

$f$ we believe that teacher research matters now more than ever, then we need to return attention to ourselves as teacher-researchers. As educators, what do we believe in? How can we investigate our teaching assumptions and teach grounded in what we know and believe about children and how they learn?

Shelly Harwayne says it eloquently:

Classroom practice must be based on richly understood and deeply held beliefs about how children learn... In other words, what teachers say and do and how they engage with children must have theoretical underpinnings. Their practice is not based on a publisher's set of directions, or a handbook filled with teaching tips, but on concepts they themselves have examined carefully. (2000, p. 26) 
"Richly understood and deeply held beliefs." How do we access them to examine them carefully? Self-reflection has always been a cornerstone of good teaching - and a crucial tool for teacher-researchers. We take notes, write in journals, keep teaching notebooks, and engage in deep conversations with each other about what we believe and what we are seeing. But it can help to take a different perspective to get at a deeper level of what we believe is essential in our experiences and in our teaching.

"Crystallization" is an intriguing new approach in qualitative research that has emerged in recent years as a kind of three-dimensional data analysis strategy that welcomes the new lens that artistic thinking can bring to research, whether it is storytelling, painting, poetry-writing, metaphor, or photography (Ellingson, 2008; Janesick, 1998; Richardson, 1994). It expands the field of data collection and analysis. Crystallization makes room for those creative leaps in thinking that teacher researchers need to help ground their work.

The term crystallization was coined by Laurel Richardson as a method of analysis that included creative forms of representation in order to tap deeper thinking (Richardson, 1994). The method, as detailed by Richardson, uses crystals as a metaphor to describe the data analysis process:

[Crystallization] combines symmetry and substance with an infinite variety of shapes, substances, transmutations, multidimensionalities, and angles of approach... Crystallization provides us with a deepened, complex, thoroughly partial understanding of the topic. Paradoxically, we know more and doubt what we know. (p. 522)

Other researchers since Richardson have built on her original work. Laura Ellingson (2008) elaborates on Richardson's articulation of crystallization to include multigenre representations and encourages researchers to be open in selecting genres that best represent the truths in their research. She further suggests that crystallization provides an effective approach to richly describing our findings as we "encounter and make sense of data through more than one way of knowing" (p. 11).

Valerie Janesick (2000) has used this method extensively in her work with researchers, with the idea that the researcher uses other disciplines to help understand findings. By including different genres such as storytelling, poetry, artistic expression, visual thinking, live performance, and so on, we have more and more angles of vision on a particular topic of research question (Ellingson, 2008). 
Crystallization can offer possibilities to represent ways of producing knowledge about a particular phenomenon through generating a deepened, complex interpretation.

\section{Crystallization Using Stories}

For example, I'm working with a group of new teachers. We are seeking to understand what is central in our teaching. Rather than discuss or journal about "what is central in my teaching," I asked them for two stories:

First, "Tell me about a time this year when you felt like you were born to teach."

Katie told the following story:"It was just really simple: we were all sitting on the floor, and I finished reading a book to the kids, and I said, 'OK, turn to one or two people near you and start talking about your questions.' You know they're all sitting there talking---and I was walking through them, kind of just sitting down and listening to some of their questions and seeing everybody chatting with each other. That was really---things like that are: ok, this is good."

"And on the other hand,"I asked,"Tell us a story about a time when you were in the classroom and you wished you'd never been born?"

Katie: (laughter) "Yeah, those happen, too. Let me think. In my last period class of the day, one time, I went through a whole lesson and explained something and gave them time to work on it, and right away someone raised her hand and said, 'Um, I don't understand. What were we supposed to do here?' I had to explain again. And then another kid raised his hand---pretty soon, there are 10 kids coming up to me and saying, 'I don't understand. What do we do?' And then I just knew, Gosh... I didn't do this right, this isn't ok, I don't know what else to say. I just felt kind of frustrated and bad about myself---because I obviously didn't do a very good job communicating. Maybe it's a bad lesson. And I thought, 'What do I do now?'"

So, with these two stories in mind, I asked Katie another question to take us a little deeper:"Do you see any relationship between those two stories?" 
"I guess I was just thinking what I see in my experience when I felt really good about it, it was that I was so excited to see that they were independent learners... And I think that is when it is frustrating is when they don't take the ball and run with it. It's when they really need me to almost do it for them. I guess that would be the big thing. The best parts about teaching for me, the best days are when the kids are really creating the lesson and they're really taking the learning themselves."

So, what we discovered is central to Katie's philosophy is a belief in children being able to be independent learners. When Katie told these two stories and compared the beliefs they represented, she engaged in a different kind of introspection, an analysis using "crystallization."

\section{Picture Books as a Starting Point}

In my teacher researcher group, we've all been looking closely at one student we work with that we are intrigued by or wondering about. Of course, we have samples of student work, anecdotal notes, and interviews. We also used crystallization to look at each student through fresh-and positive-eyes. We read aloud the book What's the Most Beautiful Thing You Know About Horses (1998) by Richard Van Camp.

Van Camp is a member of the Dogrib nation of the Northwest Territories of Canada, and an emerging voice in the Native American literary movement. He writes this children's book in order to understand horses, since his people are not horse people and he's always been curious to learn more about them-and come to understand them. The format of his book is simple: he asks different people, "What's the most beautiful thing you know about horses?" He receives responses such as: "The most beautiful thing about horses is that they always find their way home" and "I love their breath. You can feel their breath move through their chest. They stare at you as they breathe. Their soul comes right out."

After we read the book aloud and shared the vivid and colorful illustrations, we all wrote on the prompt:"What's the most beautiful thing you know about...your student?"

After a ten-minute quickwrite, we shared our writing in partners, and then with the whole group. As we discussed our discoveries, we found a different way to approach our understanding of each student-and how we might work with him or her. 
Sandy wrote that the most beautiful thing about Jack is "when he is excited about something, his face lights up as if it is the best idea he has ever been part of. He is at the same time, joyous and serious, determined and open, elated and hard-working." Sandy is determined to try to tap into this energy more intentionally.

Erika decided, "The most beautiful thing I know about Skye is her smile and the quirky, flirty way she said, 'Maybe I will.' When she gives me hints of confidence like this, I'm going to believe her and pursue it."

Rob wrote about his case study's "quiet determination to succeed that I could not see at first." This realization, in turn, sparked Rob's "determination to stick with him and share in his vision of success."

It's important to see-and re-see-our students. What we can recognize as "the most beautiful thing we know about them" can lead us to see new possibilities in our work together.

\section{Imagine a Dinner Party}

Crystallization enables teacher-researchers to push the envelope of what is possible, particularly in terms of integrating narrative, poetic, and artistic thinking with our other data and the patterns we are finding. One of the other benefits is the joy in creativity that can come with expanding our horizons as teacher-researchers. This last fall, everyone in my teacher-research group had framed her research question and was collecting data and beginning to have conversations about the community of professional books and authors that might enrich their research. We turned to a very playful-and informative-crystallization endeavor as a way to discover our scholarly community.

I encouraged teachers to imagine some of their favorite teacherresearchers, theorists and important people from their lives attending a dinner party to discuss their research question. We heard teacher-researchers envisioning conversations about community with Debbie Miller, Parker Palmer, and Jerry Garcia. When you imagine what people with different interests would consider in discussing your research question, you can cut through accepted notions of what the critical issues are. 
For our next step, everyone planned a dinner party where they invited a group of people to get together and discuss their teacher-research question. The framework was simple:

1. Invite a minimum of 6 guests - living, dead, even fictional!

2. For each guest, state the reason for including that person and what you think or hope each would contribute.

3. Be as creative as you like!

Valerie invited E.B. White, Carl Anderson, Ralph Fletcher, Linda Rief, Sandra Cisneros, and Jennifer Allen to discuss her research question: "What happens when third graders are given choice in their writing?" In these samples, you can see her reasons for her choices and what she hopes to learn from imagined dialogue at her dinner party (See Figures 1, 2, and 3).

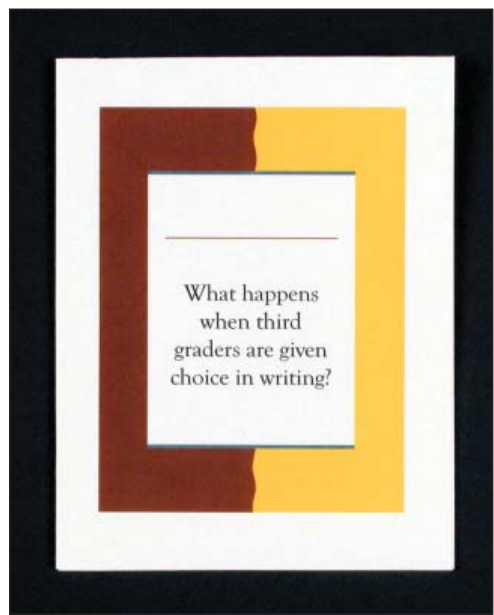

Fig. 1: Research question

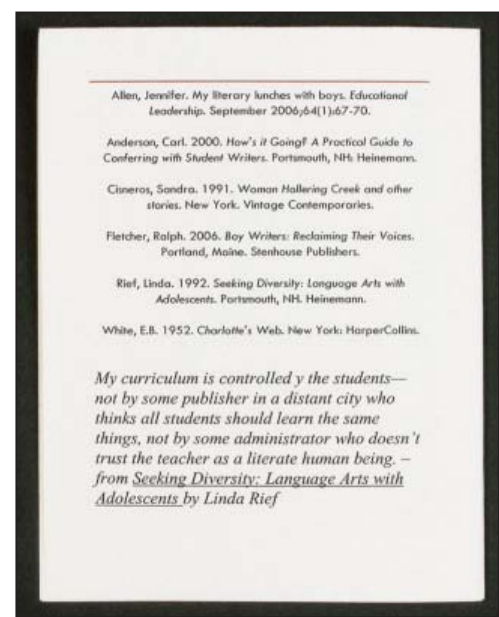

Fig. 2: The authors and their works

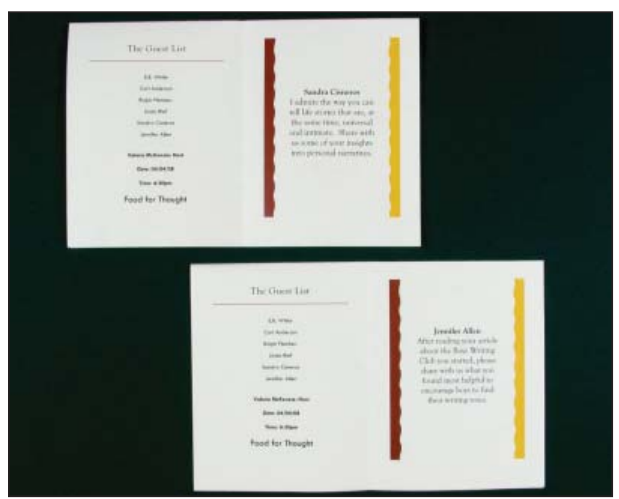

Fig. 3: The guest list 
High school teacher Susan's question centered on adolescents finding voice in their writing. Her invitation reads:

You are invited to a summer evening under the stars, where we'll savor good food, wine, and conversation. Celebrate the end of the school year and anticipate possibilities for students we are yet to meet. We'll talk about writing, voice, and how choice in writing may help students find their voices. Each of you is invited because I am grateful to have learned from you.

She invited Linda Christensen, Barbara Kingsolver, Anne Lamott, and fellow teacher Wendy Doss.

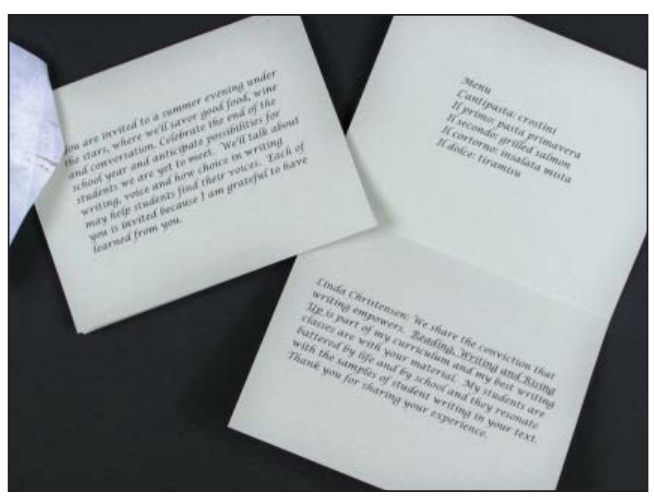

Fig. 4: Invitation and menu

After completing her dinner party invitations, Jessica reflected:

I really enjoyed the dinner party invitations. It really made me think deeply about my research question... I had to consider my question and what I am really wondering about. It also gave me the opportunity to think about the inspirations in my life, as well as teacher-researchers and other academics.

\section{Self-Reflection to Spark Conversation}

A crucial aspect of crystallization is a kind of cycle of action. As Laura Ellingson stresses, crystallization includes "a significant degree of reflexive consideration of the researcher's self and roles in the process of research design, data collection, and representation" (2009, p. 10). 
The ongoing cycle of action and reflection are at the heart of our journeys as teachers. Our group has been exploring questions like, "What drew us to teaching in the first place?"; "What are the threads in our teaching lives and commitments that ground us and keep us teaching?"; "How has our teaching practice evolved and changed?"

Rather than exploring these reflections in isolation, we have found it helpful to write, and then use our writing to spark conversations with each other that lead us to insights and revitalized classroom agendas.

We found one simple structure for self-reflection that helped us focus on our professional changes. Using the format of parallel lists, we brainstormed what we used to do and what we now do.

High school English teacher Susan was surprised to note how much her teaching practice had changed:

I used to:

1. be a grammar and usage stickler, proofing and correcting every tiny error on a student's final draft.

2. act as if mine was the only class for my students, giving lengthy reading assignments and papers.

3. have rigid deadlines with grades lowered one letter for each day late.

4. give lots of "fix-it" comments and red-pen editorial marks, and few notes on what worked well.

5. be strict about needing to keep a boundary between myself as a young(ish) teacher and adolescent students.

Now I:

1. grade one or two writing traits per paper and allow students (and myself) to break some rules and find a voice.

2. assign shorter papers and short stories as well as novels to read.

3. am more flexible with deadlines according to the needs of my students.

4. focus much more on the positive when I give students feedback.

5. allow myself to be more relaxed, smile a lot-and can still be in charge.

Cassie works with younger children and also saw big changes in her expectations for her students-and for herself: 


\section{I used to:}

1. expect children to work at their desks.

2. expect children to all write on the same topic.

3. expect kids to make friends and "behave."

4. only rarely share my own writing.

5. be afraid to challenge my students much or make work "too hard."

6. sit back and listen passively at faculty meetings.

7. expect to be a classroom teacher forever.

\section{Now I:}

1. encourage children to work everywhere in the room, wherever they need to.

2. encourage children to choose to write on their own topics.

3. model and teach what cooperation and being friends looks like.

4. share my stories, poems, and all kinds of writing all the time.

5. figure out what each of my kids can do, and set high expectations for their work.

6. speak up and take action, volunteering to lead committees and advocate for new policies.

7. think about going into a leadership position in literacy and curriculum.

Cassie's reflection led to dialogue in our group about how changes in our teaching and evolving practices can help map out future directions for our work. Most importantly, we had the opportunity for rich conversations about our classroom practice, stories from the classroom, and evolving plans. We found this to be a great way to start our meeting time together. Depending on the amount of time you have, you might also use it as a closing reflection, or write your parallel lists at one session, and open with the conversation about them at the next meeting.

Though our teaching situations are different, we are all in this work together. We found it invigorating to give ourselves the time to follow up on our quiet reflection and pave the way for renewed action.

Teacher-researchers are finding many benefits to integrating the notion of crystallization into their teacher-research. The creativity and conversation are invigorating-and it's also a way to intentionally bring our teacher voices into our work. Using narrative and story, personal images and poetry bring the reality of our teaching and living experiences to our audiences. 
As we move into the $21^{\text {st }}$ century, it is important to remember that teacherresearch is a gift: to the profession, helping us change the way we see old problems and bring us new solutions; to research communities, showing us new research strategies such as crystallization, and how we might take risks in writing up our research; and to ourselves, reminding us of the energy and passion in learning that made us teachers in the first place. Teacher-research may not give us all the answers we crave, but it will help us find creativity and joy in living our questions.

\section{References}

Ellingson, L. (2008). Engaging crystallization in qualitative research. Thousand Oaks, CA: Sage Publications.

Harwayne, S. (2000). Lifetime guarantees. Portsmouth, $\mathrm{NH}$ : Heinemann.

Janesick, V. (1998). Stretching exercises for qualitative researchers. Thousand Oaks, CA:Sage Publications.

Janesick, V. (2000). "The choreography of qualitative research design: Minuets, improvisations, and crystallization." In N.K. Denzin \& Y.S. Lincoln (Eds.) Handbook of qualitative research (pp. 66-81). Thousand Oaks, CA: Sage Publications.
Richardson, L. (1994). Writing: A method of inquiry. In N.K. Denzin \& Y.S. Lincoln (Eds.) Handbook of qualitative research ( $\mathrm{pp}$. 516-529). Thousand Oaks, CA: Sage Publications.

Van Camp, R. (1998). What's the most beautiful thing you know about horses? San Francisco: Children's Book Press.

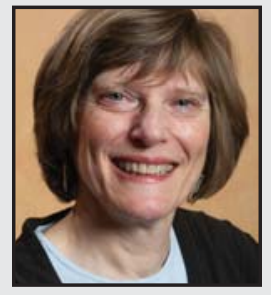

Ruth Shagoury can't imagine anything more fascinating than exploring the minds of children and adolescents as they grow as writers, readers, and language users. Though she teaches new and veteran teachers at Lewis \& Clark College in Portland, Oregon, her passion for working with children keeps her connected to classrooms, collaborating with teacherresearchers who serve largely immigrant populations as they investigate student-based approaches to literacy. She holds the Mary Stuart Rogers Chair of Education at Lewis \& Clark College.

\section{LINKTO:}

www.lclark.edu/graduate/faculty/members/ruth_shagoury/ 